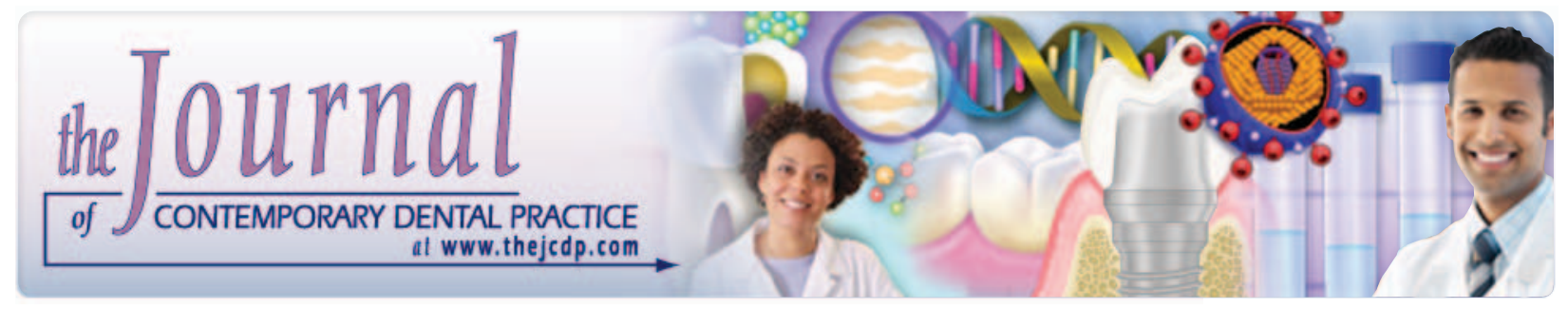

\title{
Public Awareness Level of Oral Cancer in a Group of Dental Patients
}

Ilkay Peker, DDS, PhD; Meryem Toraman Alkurt, DDS, PhD

\section{Abstract}

Aim: The aim of this study was to evaluate levels of public awareness and knowledge about early signs and risk factors of oral cancer among a group of dental patients in Turkey.

Methods and Materials: This study included 1022 participants. Sociodemographic information of patients was obtained. A questionnaire about awareness and knowledge of oral cancer and early signs and risk factors related to the disease was completed by two examiners. Data were statistically analyzed with descriptive analyses, crosstabs and chi-square tests.

Results: In total $60.7 \%$ of participants had never heard of oral cancer. While $79.2 \%$ of the participants were unaware of the early signs related to oral cancer, $29.9 \%$ of them were unaware of risk factors of the disease. There were no statistically significant differences between age, gender, and education levels for awareness of risk factors. Statistically significant differences were found between age and gender and no statistically significant difference was found between education levels for awareness of early signs.

Conclusion: This study showed that public awareness and knowledge about oral cancer were insufficient in Turkey.

Clinical Significance: There is an important need to inform the public about oral cancer, its risk factors, and early signs of the disease. Media campaigns can be useful to raise oral cancer awareness.

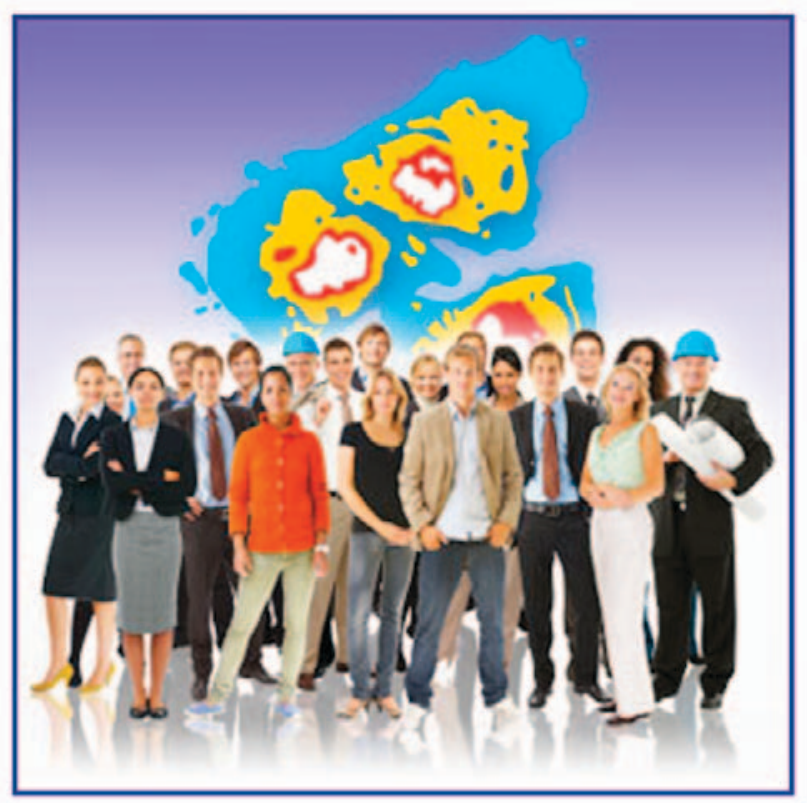

Keywords: oral cancer, public awareness, oral cancer knowledge, risk factors, early signs

Citation: Peker I, Alkurt MT. Public Awareness Level of Oral Cancer in a Group of Dental Patients. J Contemp Dent Pract [Internet]. 2010 March; 11(2):049-056. Available from: http://www.thejcdp. com/journal/view/volume11-issue2-peker.

\section{Introduction}

Oral cancer is a major public health problem, with almost 130,000 deaths worldwide annually; ${ }^{1}$ it is more common than Hodgkin's disease; carcinoma of the brain, liver, bone, thyroid gland, stomach, or ovaries; or cancer of the cervix. ${ }^{2}$ It was reported 


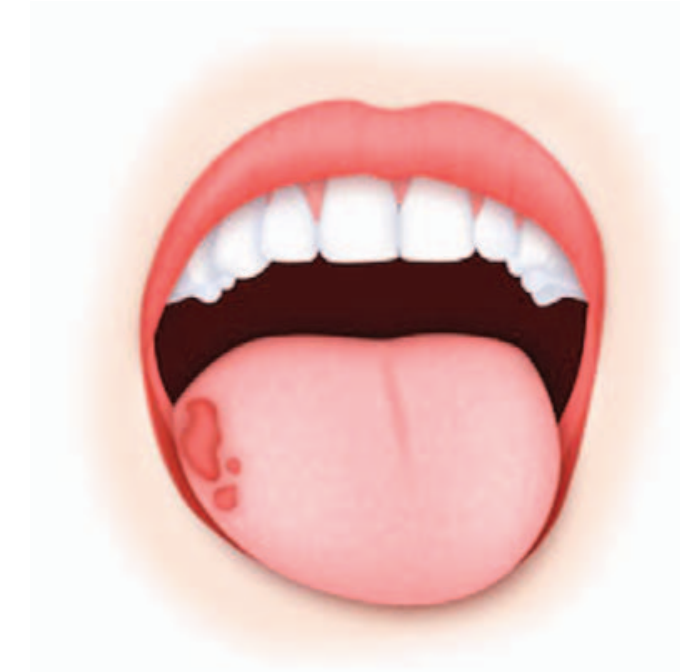

that oral cancer ranks 12th among all cancers ${ }^{2}$ and it is the 9th most common cancer in white males and the 5th most common in African American males. ${ }^{3}$

Unfortunately, approximately $50 \%$ of oral cancers are identified in advanced stages (stage III or IV), requiring aggressive treatment and associated morbidity, and resulting in higher mortality rates. ${ }^{4}$ However, stage at diagnosis is the most important prognostic indicator for oral cancer. ${ }^{-}$ Functional, aesthetic, and psychological outcomes of treatment can lead to a significant reduction of patients' quality of life ${ }^{\frac{6,7}{7}}$ as well as high social costs (roughly estimable as high as US $\$ 4$ billion worldwide annually). ${ }^{1}$ Also, patients diagnosed with localized tumors have a five-year survival rate of $80 \%$, whereas patients diagnosed with regional metastasis have a five-year survival rate of $40 \%$.

The visual access to oral mucosa is so easy that early detection is theoretically simple; despite this, the proportion of oral cancer cases diagnosed at an early stage is still less than about $50 \%{ }^{-}{ }^{9}$ General lack of knowledge and awareness about this cancer among both the general population and health care professionals play an important role in diagnostic delay. ${ }^{10}$ Previous studies ${ }^{11-14}$ in different cultures and societies showed that public awareness of signs, symptoms, and risk factors associated with oral malignancies is generally poor. According to our knowledge, public awareness about signs, symptoms, and risk factors associated with oral cancer among the Turkish population had not been investigated.

The purpose of this study was to evaluate the levels of public awareness and knowledge about early signs and risk factors of oral cancer according to age, gender, and education levels among a group of Turkish dental patients.

\section{Methods and Materials}

This study included 1022 dental patients (552 females, 470 males) aged 16 years and over who applied to Gazi University Faculty of Dentistry, Department of Oral Diagnosis and Radiology. The data collection was conducted in the period of January-March 2008; participation was a voluntary basis. All potential respondents were clearly advised that participation was anonymous and confidentiality of the response was guaranteed.

A modified questionnaire used in previous studies $^{13,15.16}$ was prepared to assess public awareness and knowledge about risk factors, signs, and symptoms associated with oral cancer. The survey contained 16 items in four parts: sociodemographic information (3 items), awareness and knowledge of oral cancer (5 items), risk factors of the disease (5 items), and early signs of it ( 3 items). After sociodemographic information including age, gender, and education levels were obtained, participants were asked whether they had ever heard of oral cancer. To detect their level of knowledge, further questions were asked to detect whether they had any information on the subject, ranging from "a lot" to "nothing at all"; they also were asked from where this information had been gained. The survey also questioned the respondents where they would seek assistance if they suspected that they or their relatives might have oral cancer and they were asked whether they had received such an oral cancer examination within the last year (Table 1).

Participants were questioned about their opinion concerning five known major risk factors and three clinical signs for oral cancer according to a four-point Likert-type response scale (Table 1). All evaluations were carried out face-to-face in a period of 12 to 15 minutes by two specialists of oral diagnosis and radiology with at least 12 years of experience.

\section{Data analysis}

The responses "definitely increases" for the first three risk factors and "definitely does not increase" for last two factors were defined as correct (Table 
Table 1. The questionnaire used in the study.

Sociodemographic information

1. Age:

2. Gender: Female Male

3. Education level: Elementary school

Awareness and knowledge of oral cancer

4. Have you ever heard of oral cancer? Yes No

5. Do you have any information about mouth, tongue, or lip cancer?

_ Yes, a lot Yes, a little No

6. If you have any information, where did you get it?
a) Television, radio, or newspaper
b) Friends and/or environment
c) Internet
d) Dentist

7. Where would you seek assistance if you suspect you or your relatives have oral cancer?
a) Ear, nose, and throat specialist
b) Medical doctor
c) Dentist

8. Have you received an oral cancer examination within the last year? a) Yes b) No c) I don't know

Risk factors associated with mouth, tongue, or lip cancer

9. In your opinion, could smoking increase the risk of oral cancer?
a) Definitely does not increase risk
b) Probably does not increase risk.

c) Probably increases risk

d) Definitely increases risk

10. In your opinion, could regular consumption of alcohol increase the risk of oral cancer?
a) Definitely does not increase risk
b) Probably does not increase risk.
c) Probably increases risk
d) Definitely increases risk

11. In your opinion, could excessive exposure to sunlight increase the risk of oral cancer?
a) Definitely does not increase risk
c) Probably increases risk
b) Probably does not increase risk.
d) Definitely increases risk

12. In your opinion, could eating hot, spicy foods increase the risk of oral cancer?
a) Definitely does not increase risk
b) Probably does not increase risk.
c) Probably increases risk
d) Definitely increases risk

13. In your opinion, could frequently biting the cheek or lip increase the risk of oral cancer?
a) Definitely does not increase risk
b) Probably does not increase risk.
c) Probably increases risk
d) Definitely increases risk

Early signs associated with mouth, tongue, or lip cancer

14. In your opinion, could painless white patches be an early sign of oral cancer?
a) Definitely, no
b) Probably, no
c) Probably, yes
d) Definitely, yes

15. In your opinion, could painless red patches be an early sign of oral cancer?
a) Definitely, no
b) Probably, no
c) Probably, yes
d) Definitely, yes

16. In your opinion, could sore and bleeding lesions be an early sign of oral cancer?
a) Definitely, no
b) Probably, no
c) Probably, yes
d) Definitely, yes

1). A "risk factor knowledge score" was created

by summing the number of correct responses to the five items and the results were evaluated into four categories: 0, 1, 2, and 3 and above. The response "definitely yes" was defined as correct for all early signs. An "early signs knowledge score" was created by summing the number of correct responses to the three symptoms and the results were evaluated into four categories: 0,1 , 2 , and 3 so that two points comprising point of risk factors (PRF) and point of early signs (PES) were obtained for each participant.

Obtained data were statistically analyzed with descriptive analyses, crosstabs, and chi-square tests using SPSS software, version 15.0, for Windows (SPSS Inc., Chicago, Illinois, USA).
PRF and PES of participants were statistically analyzed with crosstabs and chi-square tests according to age, gender, and education level. To assess age groups, subjects were divided into two groups: 16-39 years and 40 and over.

\section{Results}

The ages of the 1022 subjects ranged from 16 to 77 years, with the mean age being 36.5 . There were 618 patients $(60.5 \%)$ in the $16-39$ age group and 404 patients (39.5\%) in the $40-77$ age group. The majority of the subjects $(44 \%$, $\mathrm{n}=450$ ) had a high school education, followed by university $(40.4 \%, n=413)$ and elementary school $(15.6 \%, n=159)$ respectively. 
Only $39.3 \%(n=402)$ said that they had heard of oral cancer and $60.7 \%(n=620)$ had never heard of it; also the majority of participants $(67.8 \%$, $\mathrm{n}=693$ ) knew nothing about the disease. Most of the subjects who had heard of oral cancer $(14.2 \%, n=145)$ reported they had received information about oral cancer from television, radio, or newspaper and environment. Only $48.2 \%(n=493)$ thought that they would seek assistance from a dentist if they suspected that they or their relatives had oral cancer and also only $0.9 \%(n=10)$ reported having had an oral cancer examination within the last year.

Percentages of awareness and knowledge about oral cancer are shown in Table 2.

The risk factors associated with oral cancer that were most often correctly identified by the participants were smoking $(57.6 \%, \mathrm{n}=589)$; regular consumption of alcohol $(27.9 \%, \mathrm{n}=285)$; excessive exposure to sunlight ( $15 \%, n=153)$; eating hot, spicy foods $(9.9 \%, n=101)$; and biting the cheek or lip $(6.8 \%, n=69)$ respectively. The early signs of oral cancer that were most often correctly identified by the participants were sore and bleeding lesions (17.5\%, $n=179)$, painless white patches $(6.8 \%, n=70)$, and red patches $(6.5 \%, n=66)$ respectively.
While no statistically significant differences $(p>0.05)$ were found between age groups and gender for PRF, there were statistically significant differences $(p<0.05)$ between age groups and gender for PES. Distribution and analyses of PRF and PES are shown in Table 3 for age groups and in Table 4 for gender. No statistically significant differences $(p>0.05)$ were found between education levels for both PRF and PES (Table 5).

\section{Discussion}

The results of this study showed that levels of public awareness and knowledge about early signs and risk factors of oral cancer were low in a group of Turkish dental patients. As far as we can ascertain, this study is the first community-based study to evaluate public awareness and knowledge about early signs and risk factors of oral cancer in Turkey.

Public awareness and knowledge of oral cancer were investigated in several studies performed in different communities and countries. Although these studies showed different results, generally the level of public awareness and knowledge about the disease were found insufficient. The rates of individuals having never heard of oral cancer

Table 2. Percentages of awareness and knowledge about oral cancer.

\begin{tabular}{|c|c|c|c|}
\hline \multicolumn{2}{|l|}{ Items } & N (Number) & Percent (\%) \\
\hline \multirow{2}{*}{ Have you ever heard of oral cancer? } & Yes & 402 & 39.3 \\
\hline & No & 620 & 60.7 \\
\hline \multirow{3}{*}{$\begin{array}{l}\text { Do you have any information about } \\
\text { mouth, tongue, or lip cancer? }\end{array}$} & Yes, a lot & 108 & 10.6 \\
\hline & Yes, a little & 221 & 21.6 \\
\hline & No & 693 & 67.8 \\
\hline \multirow{4}{*}{$\begin{array}{l}\text { If you have any information, where } \\
\text { did you get it? }\end{array}$} & TV, radio, or newspaper & 145 & 14.2 \\
\hline & Friends, environment, etc. & 145 & 14.2 \\
\hline & Internet & 51 & 5.0 \\
\hline & Dentist & 19 & 1.9 \\
\hline \multirow{3}{*}{$\begin{array}{l}\text { Where would you seek assistance } \\
\text { if you suspect you or your relatives } \\
\text { have oral cancer? }\end{array}$} & $\begin{array}{l}\text { Ear, nose, and throat } \\
\text { specialist }\end{array}$ & 346 & $33 . .9$ \\
\hline & Medical doctor & 183 & 17.9 \\
\hline & Dentist & 493 & 48.2 \\
\hline \multirow{3}{*}{$\begin{array}{l}\text { Have you received an oral cancer } \\
\text { examination within the last year? }\end{array}$} & Yes & 10 & 0.9 \\
\hline & No & 952 & 93.2 \\
\hline & I don't know & 60 & 5.9 \\
\hline
\end{tabular}


Table 3. Distribution and analyses of PRF and PES for age groups.

\begin{tabular}{|c|c|c|c|c|c|c|c|}
\hline \multirow{2}{*}{ Variables } & \multirow{2}{*}{ Points } & \multicolumn{2}{|c|}{ Age groups } & \multirow{2}{*}{$\begin{array}{l}\text { Total } \\
\text { N (\%) }\end{array}$} & \multirow{2}{*}{$\begin{array}{l}\text { Chi- } \\
\text { square }\end{array}$} & \multirow{2}{*}{ Df } & \multirow{2}{*}{$p$ value } \\
\hline & & $16-39$ yrs & $40+y r s$ & & & & \\
\hline \multirow{4}{*}{ PRF } & $\begin{array}{l}\mathrm{PRF}=0 \\
\mathrm{~N}(\%)\end{array}$ & $196(64.1)$ & $110(35.9)$ & $306(100)$ & \multirow{4}{*}{6.935} & \multirow{4}{*}{4} & \multirow{4}{*}{0.139} \\
\hline & $\begin{array}{l}\mathrm{PRF}=1 \\
\mathrm{~N}(\%)\end{array}$ & $230(59.9)$ & $154(40.1)$ & $384(100)$ & & & \\
\hline & $\begin{array}{l}\mathrm{PRF}=2 \\
\mathrm{~N}(\%)\end{array}$ & $131(61.8)$ & $81(38.2)$ & $212(100)$ & & & \\
\hline & $\begin{array}{l}\mathrm{PRF}=3 \text { and above } \\
\mathrm{N}(\%)\end{array}$ & $61(50.8)$ & $59(49.2)$ & $120(100)$ & & & \\
\hline \multirow{4}{*}{ PES } & $\begin{array}{l}\mathrm{PES}=0 \\
\mathrm{~N}(\%)\end{array}$ & $508(62.8)$ & $301(37.2)$ & $809(100)$ & \multirow{4}{*}{10.097} & \multirow{4}{*}{3} & \multirow{4}{*}{$0.018^{*}$} \\
\hline & $\begin{array}{l}\text { PES=1 } \\
N(\%)\end{array}$ & $78(54.2)$ & $66(45.8)$ & $144(100)$ & & & \\
\hline & $\begin{array}{l}\mathrm{PES}=2 \\
\mathrm{~N}(\%)\end{array}$ & $15(44.1)$ & 19 (55.9) & $34(100)$ & & & \\
\hline & $\begin{array}{l}\mathrm{PES}=3 \text { and above } \\
\mathrm{N}(\%)\end{array}$ & $17(48.6)$ & $18(51.4)$ & $35(100)$ & & & \\
\hline
\end{tabular}

Table 4. Distribution and analyses of PRF and PES for gender.

\begin{tabular}{|c|c|c|c|c|c|c|c|}
\hline \multirow{2}{*}{ Variables } & \multirow{2}{*}{ Points } & \multicolumn{2}{|c|}{ Gender } & \multirow{2}{*}{$\begin{array}{l}\text { Total } \\
\text { N (\%) }\end{array}$} & \multirow{2}{*}{$\begin{array}{l}\text { Chi- } \\
\text { square }\end{array}$} & \multirow{2}{*}{ Df } & \multirow{2}{*}{$p$ value } \\
\hline & & Female & Male & & & & \\
\hline \multirow{4}{*}{ PRF } & $\begin{array}{l}P R F=0 \\
N(\%)\end{array}$ & $153(50)$ & $153(50)$ & $306(100)$ & \multirow{4}{*}{4.342} & \multirow{4}{*}{4} & \multirow{4}{*}{0.362} \\
\hline & $\begin{array}{l}\mathrm{PRF}=1 \\
\mathrm{~N}(\%)\end{array}$ & 207 (53.9) & $177(46.1)$ & $384(100)$ & & & \\
\hline & $\begin{array}{l}\mathrm{PRF}=2 \\
\mathrm{~N}(\%)\end{array}$ & $120(46.6)$ & $92(43.4)$ & $212(100)$ & & & \\
\hline & $\begin{array}{l}\mathrm{PRF}=3 \text { and above } \\
\mathrm{N}(\%)\end{array}$ & $72(60)$ & $48(40)$ & $120(100)$ & & & \\
\hline \multirow{4}{*}{ PES } & $\begin{array}{l}P E S=0 \\
N(\%)\end{array}$ & $416(53.4)$ & $393(48.6)$ & $809(100)$ & \multirow{4}{*}{10.871} & \multirow{4}{*}{3} & \multirow{4}{*}{$0.012^{*}$} \\
\hline & $\begin{array}{l}P E S=1 \\
N(\%)\end{array}$ & $94(65.3)$ & $50(34.7)$ & $144(100)$ & & & \\
\hline & $\begin{array}{l}\mathrm{PES}=2 \\
\mathrm{~N}(\%)\end{array}$ & $21(61.8)$ & $13(38.2)$ & 34 (100) & & & \\
\hline & $\begin{array}{l}\mathrm{PES}=3 \text { and above } \\
\mathrm{N}(\%)\end{array}$ & $21(60)$ & $14(40)$ & 35 (100) & & & \\
\hline
\end{tabular}


Table 5. Distribution and analyses of PRF and PES for education levels.

\begin{tabular}{|c|c|c|c|c|c|c|c|c|}
\hline \multirow[b]{2}{*}{ Variables } & \multirow[b]{2}{*}{ Points } & \multicolumn{3}{|c|}{ Education levels } & \multirow{2}{*}{$\begin{array}{l}\text { Total } \\
\text { N (\%) }\end{array}$} & \multirow{2}{*}{$\begin{array}{c}\text { Chi- } \\
\text { square }\end{array}$} & \multirow[b]{2}{*}{ Df } & \multirow[b]{2}{*}{$p$ value } \\
\hline & & $\begin{array}{c}\text { Elementary } \\
\text { school }\end{array}$ & $\begin{array}{l}\text { High } \\
\text { school }\end{array}$ & University & & & & \\
\hline \multirow{4}{*}{ PRF } & $\begin{array}{l}\mathrm{PRF}=0 \\
\mathrm{~N}(\%)\end{array}$ & $49(16)$ & $138(45.1)$ & 119 (38.9) & $306(100)$ & \multirow{4}{*}{12.926} & \multirow{4}{*}{8} & \multirow{4}{*}{0.114} \\
\hline & $\begin{array}{l}\mathrm{PRF}=1 \\
\mathrm{~N}(\%)\end{array}$ & $58(15.1)$ & $154(40.1)$ & $172(44.8)$ & $384(100)$ & & & \\
\hline & $\begin{array}{l}\mathrm{PRF}=2 \\
\mathrm{~N}(\%)\end{array}$ & $31(14.6)$ & $95(44.8)$ & $86(40.6)$ & $212(100)$ & & & \\
\hline & $\begin{array}{l}\mathrm{PRF}=3 \text { and above } \\
\mathrm{N}(\%)\end{array}$ & $21(17.5)$ & $63(52.5)$ & $36(30)$ & $120(100)$ & & & \\
\hline \multirow{4}{*}{ PES } & $\begin{array}{l}\mathrm{PES}=0 \\
\mathrm{~N}(\%)\end{array}$ & $124(15.3)$ & $366(45.2)$ & $319(39.4)$ & $809(100)$ & \multirow{4}{*}{5.198} & \multirow{4}{*}{6} & \multirow{4}{*}{0.519} \\
\hline & $\begin{array}{l}\mathrm{PES}=1 \\
\mathrm{~N}(\%)\end{array}$ & $23(16)$ & $55(38.2)$ & $66(45.8)$ & $144(100)$ & & & \\
\hline & $\begin{array}{l}\mathrm{PES}=2 \\
\mathrm{~N}(\%)\end{array}$ & $8(23.5)$ & $12(35.3)$ & $14(41.2)$ & $34(100)$ & & & \\
\hline & $\begin{array}{l}\text { PES=3 and above } \\
\mathrm{N}(\%)\end{array}$ & $4(11.4)$ & $17(48.6)$ & $14(40)$ & $35(100)$ & & & \\
\hline
\end{tabular}

were reported as $4.4 \%$ in Great Britain, $\frac{13}{40} 40 \%$ in the North Carolina region of the USA, ${ }^{16} 44 \%$ in London, ${ }^{11}$ and $70 \%$ in blacks or Hispanics living in the Florida region of the USA. ${ }^{14}$ In the present study, $60.7 \%$ of the participants reported having never heard of oral cancer and $67.8 \%$ of them knew nothing about it. However, these results were relatively high in comparison with previous studies; this condition was probably associated with social and cultural differences and/or campaigns and activities aiming to improve public consciousness in other countries.

Oral cancer prevention campaigns based on media advertising, such as TV and radio broadcasts, newspaper articles, advertisements on billboards, and oral cancer information leaflets can be useful to raise cancer awareness, ${ }^{10,17,18}$ but such increased awareness is generally transitory and the message is sometimes misunderstood. ${ }^{19}$ These activities must be well presented and easily understandable by all age groups and various social strata..$^{10}$ In this study, most of the subjects reported they received information about oral cancer from television, radio, or newspaper or friends and environment; only a small number of them reported receiving information from a dentist. So, well-arranged and easily understandable campaigns may be effective for prevention and early diagnosis of oral cancer.

Although oral cancer therapy requires multidisciplinary approaches including surgery, radiation therapy, chemotherapy, and sometimes esthetics reconstruction, ${ }^{20}$ oral health care providers have prime importance especially for diagnosis at early stages. Cruz et al. ${ }^{12}$ reported lack of agreement between public and medical health providers about what type of health professional is most appropriate to diagnose oral cancer; those at high risk say they would most probably go to a physician if they notice any signs or symptoms, whereas the physicians think dentists are the most appropriate health care professional to diagnose oral cancer. In this study, over half the participants reported that they would seek assistance from an ear, nose, and throat specialist or medical doctor if they had suspected that either they or their relatives might have oral cancer; the remainder reported they would seek assistance from a dentist. But the subjects possibly may have been influenced in their selection of a dentist since this study was carried out in a dental school. Probably the rate of participants thinking to utilize an ear, nose, and throat specialist or a medical doctor would 
increase if the study was carried out in another center. Although seeking out an ear, nose, and throat specialist or a medical doctor would not be incorrect, it must be known that the dentist's task is whole oral health, so an increase in periodic controls may also increase public awareness, knowledge, and early detection of oral cancer.

Actually, all health care providers have the opportunity to provide routine oral cancer examinations to their patients. The American Cancer Society currently recommends that a cancer-related checkup, including an examination of the oral region, occur during a general periodic health examination for men and women aged 20 years and older. ${ }^{21}$ Previous studies showed the rates of receiving an oral cancer examination within the past year were $23 \% 16$ and $19.5 \% .{ }^{14}$ In this study, $6.8 \%$ of the participants reported having had an oral cancer examination within last year. This result was lower than that found in previous studies. This condition may be related to individuals not having a regular health examination including oral and whole-body checkup. Also, awareness and knowledge on the part of all health care providers play important roles in early detection of oral cancer as well as public awareness and knowledge..$^{12}$

Public awareness and knowledge about risk factors of oral cancer were investigated and it was reported that the most correctly identified risk factor in previous studies was smoking and/ or tobacco use. $\frac{11,14-16}{6}$ Whereas regular alcohol consumption is a high risk factor for oral cancer, the association between alcohol and oral cancer was not known by many people. ${ }^{11}$ Among adults in Florida, knowledge concerning risk factors was

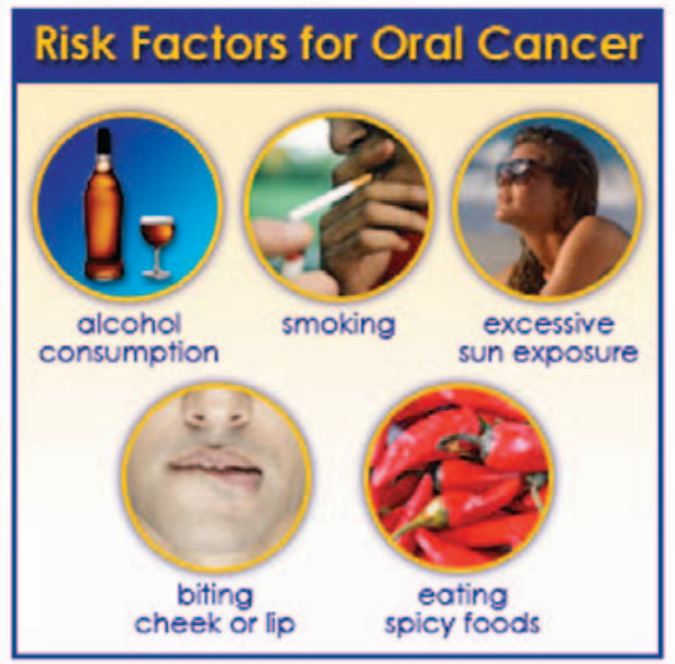

found as $95.4 \%$ for smoking and/or tobacco use, $44.1 \%$ for regular alcohol consumption, and $61.5 \%$ for sun exposure. ${ }^{14}$ In another study ${ }^{15}$ carried out in the New York State and New Jersey area, knowledge related to these factors was found as $76 \%$ for smoking and/or tobacco use; $25 \%$ for regular alcohol consumption; $25 \%$ for sun exposure; $40 \%$ for eating hot, spicy foods; and $24 \%$ for biting the cheek or lip. In this study, the most "correctly" identified risk factor was smoking $(57.6 \%)$, followed by regular consumption of alcohol (27.9\%); excessive exposure to sunlight $(15 \%)$; eating hot, spicy foods $(9.9 \%)$; and biting the cheek or lip (6.8\%). When considering the total knowledge point of the risk factors, the rate of 3 and above for risk factors correctly identified was only $11.74 \%$. These results have shown that awareness and knowledge about risk factors of oral cancer in Turkey were relatively lower than in previous studies.

Public awareness and knowledge about early signs of oral cancer were investigated in several studies and the rates of the early signs of oral cancer correctly identified were found as $33.8-53.8 \%$ for painless white patches, $24.5-47.7 \%$ for painless red patches, and $57-66.5 \%$ for sore and bleeding lesions. ${ }^{13,14}$ In this study, the rates of knowledge about the early signs were $6.8 \%$ for painless white patches, $6.5 \%$ for painless red patches, and $17.5 \%$ for sore and bleeding lesions. These results were remarkably low.

Several sociodemographic factors may affect public awareness and knowledge of the risk factors and early signs of oral cancer. It was reported that the high education level and age increase awareness and knowledge of oral cancer ${ }^{14,22}$ and that male respondents had more knowledge of risk factors for oral cancer but yet did not display higher vulnerability to oral cancer than female respondents. ${ }^{\underline{23}}$ In the present study, no statistically significant differences were found between age groups and gender for knowledge of risk factors, whereas there were statistically significant differences between age groups and gender for knowledge of the early signs. The early signs were known better in the 40 and over age group than in the 16-39 age group and by female respondents more so than males. No statistically significant differences were found between education levels for both risk factors and early signs. 
Depending on self-reported data may be considered to be a limitation of this study. For example, many respondents might have received an oral cancer examination but cannot remember it and/or they might remain unaware. Additionally, another limitation may be the format of the questions as different wordings can give different results. Also, when comparing the results of this study with those of others, it should be considered that the evaluation method and criteria of each study may change the results.

\section{Conclusion}

According to the results of this study, it is clear that public awareness and knowledge about oral cancer, risk factors, and early signs of the disease were insufficient in Turkey, as has also been found in many other countries.

\section{Clinical Significance}

There is an important need to inform the public about oral cancer, its risk factors, and early signs of the disease. Campaigns including TV and radio broadcasts, newspaper articles, advertisements on billboards, and information leaflets can be useful to raise oral cancer awareness. In particular, knowledge about risk factors and early signs of oral cancer will increase both prevention and diagnosis in early stages.

\section{References}

1. Ferlay J, Bray F, Pisani P, Parkin DM. Globocan 2002: cancer incidence, mortality and prevalence worldwide. IARC Cancer Base No. 5. Version 2.0. Lyon: IARC Press; 2004.

2. Jemal A, Thomas A, Murray T, Thun M. Cancer statistics, 2002. CA Cancer J Clin. 2002; 52(1):23-47.

3. Howe HL, Wu X, Ries LA, Cokkinides V, Ahmed F, Jemal A, Miller B, Williams $M$, Ward E, Wingo PA, Ramirez A, Edwards BK. Annual report to the nation on the status of cancer, 1975-2003, featuring cancer among U.S. Hispanic/Latino populations. Cancer. 2006; 107(8):1711-42.

4. Shiboski CH, Shiboski SC, Silverman S Jr.
Trends in oral cancer rates in the United States, 1973-1996. Community Dent Oral Epidemiol. 2000; 28(4):249-56.

5. Morelatto RA, Herrera MC, Fernández EN, Corball AG, López de Blanc SA. Diagnostic delay of oral squamous cell carcinoma in two diagnosis centers in Córdoba Argentina. J Oral Pathol Med. 2007; 36(7):405-8.

6. Graham JA, Horowitz AM, Canto MT. Coverage and quality of oral cancer information in selected popular press: May 1998 to July 2003. J Public Health Dent. 2004; 64(4):231-6.

7. van der Meij EH, Bezemer PD, van der Waal I. Cost-effectiveness of screening for the possible development of cancer in patients with oral lichen planus. Community Dent Oral Epidemiol. 2002; 30(5):342-51.

8. Ries LAG, Kosary CL, Hankey BF, Miller BA, Clegg L, Edwards BK, editors. SEER cancer statistics review, 1973-1996. Bethesda, MD: National Cancer Institute; 1999.

9. Patton LL. The effectiveness of communitybased visual screening and utility of adjunctive diagnostic aids in the early detection of oral cancer. Oral Oncol. 2003; 39(7):708-23.

10. Petti S, Scully C. Oral cancer knowledge and awareness: primary and secondary effects of an information leaflet. Oral Oncol. 2007; 43(4):408-15.

11. Warnakulasuriya KA, Harris $C K$, Scarrott DM, Watt R, Gelbier S, Peters TJ, Johnson NW. An alarming lack of public awareness towards oral cancer. Br Dent J. 1999; 187(6):319-22.

12. Cruz GD, Shulman LC, Kumar JV, Salazar CR. The cultural and social context of oral and pharyngeal cancer risk and control among Hispanics in New York. J Health Care Poor Underserved. 2007; 18(4):833-46.

13. West R, Alkhatib MN, McNeill A, Bedi R. Awareness of mouth cancer in Great Britain. Br Dent J. 2006; 200(3):167-9.

14. Tomar SL, Logan HL. Florida adults' oral cancer knowledge and examination experiences. J Public Health Dent. 2005; 65(4):221-30.

15. Cruz GD, Le Geros RZ, Ostroff JS, Hay JL, Kenigsberg $\mathrm{H}$, Franklin DM. Oral cancer knowledge, risk factors and characteristics of subjects in a large oral cancer screening program. J Am Dent Assoc. 2002; 133(8):1064-71; quiz 1094. 
16. Patton LL, Agans R, Elter JR, Southerland $\mathrm{JH}$, Strauss RP, Kalsbeek WD. Oral cancer knowledge and examination experiences among North Carolina adults. J Public Health Dent. 2004; 64(3):173-80.

17. McLeod NM, Saeed NR, Ali EA. Oral cancer: delays in referral and diagnosis persist. $\mathrm{Br}$ Dent J. 2005; 198(11):681-4.

18. Stahl S, Meskin LH, Brown LJ. The American Dental Association's oral cancer campaign: the impact on consumers and dentists. J Am Dent Assoc. 2004; 135(9):1261-7.

19. Humphris GM, Duncalf M, Holt D, Field EA. The experimental evaluation of an oral cancer information leaflet. Oral Oncol. 1999; 35(6):575-82.

20. Chen PH, Shieh TY, Ho PS, Tsai CC, Yang YH, Lin YC, Ko MS, Tsai PC, Chiang SL, Tu HP, Ko YC. Prognostic factors associated with the survival of oral and pharyngeal carcinoma in Taiwan. BMC Cancer. 2007; 7:101.

21. Canto MT, Kawaguchi Y, Horowitz AM. Coverage and quality of oral cancer information in the popular press: 1987-98. J Public Health Dent. 1998; 58(3):241-7.

22. Horowitz AM, Nourjah PA. Factors associated with having oral cancer examinations among US adults 40 years of age or older. J Public Health Dent. 1996; 56(6):331-5.

23. Choi Y, Dodd V, Watson J, Tomar SL, Logan HL, Edwards H. Perspectives of African Americans and dentists concerning dentist-patient communication on oral cancer screening. Patient Educ Couns. 2008; 71(1):41-51.

\section{About the Authors}

Ilkay Peker, DDS, PhD (Corresponding Author)

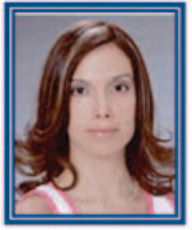

Dr. Peker is a research assistant in the Department of Oral Diagnosis and Radiology, Faculty of Dentistry at Gazi University in Ankara, Turkey. Her research interests are oral medicine, epidemiologic studies, and dentomaxillofacial imaging systems.

e-mail: drdtilkay@gmail.com

\section{Meryem Toraman Alkurt, DDS, PhD}

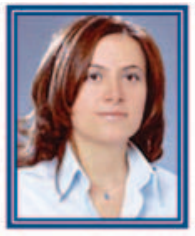

Dr. Toraman Alkurt is an assistant professor in the Department of Oral Diagnosis and Radiology, Faculty of Dentistry at Gazi University in Ankara, Turkey. Her research interests are oral medicine, epidemiologic studies, and dentomaxillofacial imaging systems.

e-mail: mtalkurt@gmail.com

\section{Acknowledgement}

The study was presented at the 1st National Oral Cancer Symposium in April 2008, in Ankara, Turkey, and was given an award by the Organization Committee. 